\title{
Changes in intraocular pressure after intravitreal injection of Ranibizumab
}

\author{
Asmaa Mohamed Fouad ${ }^{1}$, Mohamed Yasser Sayed Saif ${ }^{1,2}$, \\ Abd El Hafez, Khaled Abd ElAziz ${ }^{1}$ \\ ${ }^{1}$ Ophthalmology Department, Faculty of Medicine, Beni Suef University, Egypt \\ ${ }^{2}$ National Institute for Longevity Elderly Sciences (NILES), Beni Suef University, Egypt
}

\begin{abstract}
Background: The aim of this study was to detect changes in intraocular pressure (IOP) following initial intravitreal injection of antivascular endothelial growth factor agents anti-VEGF ranibizumab in patients presenting with macular edema due to diabetes mellitus (DM), age- related macular degeneration (ARMD), retineal vein occlusion(RVO), and myopic choroidal neovascularization (CNV) .

Methods: In this study, a prospective analysis was conducted on 40 eyes of 40 patients. IOP was measured using a goldmann applanation tonometer before injection, $24 \mathrm{~h}, 1 \mathrm{st}$ and weekly up to 8 weeks after injection. Patients were scheduled for intravitreal injection of anti-VEGF ranibizumab $(0.5 \mathrm{mg} / 0.05 \mathrm{ml})$ for the treatment of macular edema due to(DM), (RVO), (ARMD), and (CNV).

Results: It was found that there was a significant difference, but still within the normal range value in IOP measured $24 \mathrm{~h}$ after injection $(14.2 \pm 3.54 \mathrm{mmHg}$ and ranged from $(9$ : $22 \mathrm{mmHg})$ ) compared to baseline $(\mathrm{p}=0.001)$. There was no significant difference between the IOP from 1 week up to $8 \mathrm{~W}$ of ranibizumab injection.

Conclusion: This study confirms the results of previous studies that showed the safety of initial IV injection of anti-VEGF agents for IOP elevation in post-injection two months in non- glaucomatous patients.
\end{abstract}

Keywords: Intraocular pressure, ranibizumab

\section{Introduction}

Ranibizumab is an anti-vascular endothelial growth factor (anti-VEGF) agent have been developed that targets and bins the factor responsible for abnormal blood vessel growth and leakage, It inhibit its activity. (1). Ranibizumab_was the first drug designed for ocular administration, approved by the Food and Drug Administration (FDA) in 2006. (2). These anti-VEGF agents have been shown to reduce the burden of AMD , DME, and RVO by slowing or even reversing the vision loss typically associated with these diseases. (3).

The pressure of the aqueous fluid is the pressure of the fluid inside the eye. Tonometry is the method eye care professionals use to determine this. IOP is an important aspect in the evaluation of patients at risk for glaucoma .Most tonometers are calibrated to measure the pressure in millimeters of mercury mmHg. (4).

In the general population, IOP ranges between 10 and $21 \mathrm{mmHg}$ with a mean of about 15 or $16 \mathrm{mmHg}$ (plus or minus $3.5 \mathrm{mmHg}$ during a 24-hour cycle). (Hashemi, H et al., 2015) (5). 


\section{Patients and Methods}

This was a prospective, comparative clinical study that was done in $\mathrm{El}$ Fayoum Ophthalmic Hospital from March 2018 to August 2018, conducted on 40 eyes of 40 patients. Patients were scheduled for intravitreal injection of anti-VEGF ranibizumab $(0.5 \mathrm{mg} / 0.05 \mathrm{ml})$ for the treatment of diabetic macular edema, retineal vein occlusion, age- related macular degeneration, and myopic choroidal neovascularization (CNV). Their mean age was (57.22 \pm 12.89$)$.

\section{Inclusion criteria:}

-All patients who were scheduled for intravitreal injection of anti-VEGF because of diabetic macular edema DME, RVO, ARMD, and CNV.

-All patients should have normal IOP $(10-21 \mathrm{~mm} \mathrm{Hg}$ ) before the injection with no anti-glaucoma medication.

Exclusion Criteria:

-Patients with intra-ocular or extraocular inflammation

-Patients with previous intravitreal injections in the same eye within 6 months from the initiation of antiVEGF therapy.

\section{Statistical methods:}

Data were coded and entered using the statistical package SPSS (Statistical Package for the Social Sciences) version 25. Data were summarized using mean and standard deviation in quantitative data and using frequency (count) and relative frequency

\section{Results}

This study included fourty eyes that were included in our prospective study.

1.Demographic distribution

-AGE:The mean patients' age was 57.22 \pm SD 12.89 years.
-Patients with significant corneal opacity that could interfere with proper standard IOP assessment such as glaucoma or corneal disease.

-Patients who were diagnosed as having any type of glaucoma or ocular hypertension (IOP >21 $\mathrm{mmHg}$ ), or using anti-glaucoma medications.

-Patients with medical histories of any ocular trauma or surgeries other than uncomplicated phacoemulsification and posterior chamber intraocular lens implantation

All patients were subjected to: All participants will underwent for ophthalmological examination:

A complete ocular examination was done using the following:

Visual acuity measurement

Slit-lamp examination

Intraocular Pressure measurement

Gonioscopy

Fundus examination

Optical coherence tomography (OCT)

fundus fluorescein angiography (FFA)

Preoperative medications

Intravitreal injection of anti-VEGF

Postoperative IOP measurement

(percentage) for categorical data. For comparison of serial measurements within each group, repeated measures ANOVA was used (6). P-values less than 0.05 were considered statistically significant.

- SEX: This study included 19 men and 21 females as shown in fig1. 


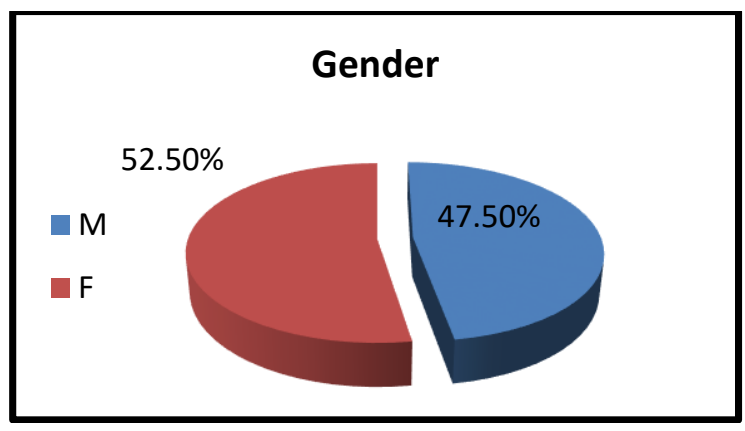

- DISEASE:

In this study, the main disease was diabetes mellitus $50 \%$

\section{Disease}

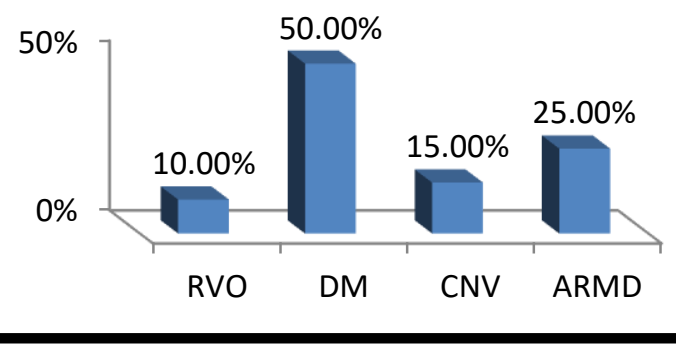

Tables(1) and fig (2): presents the percentage of each disease that was shared in this study.

\begin{tabular}{|l|l|l|l|}
\hline & & Count & $\%$ \\
\hline \multirow{3}{*}{ Disease } & RVO & 4 & $10.00 \%$ \\
\cline { 2 - 4 } & DM & 20 & $50.00 \%$ \\
\cline { 2 - 4 } & CNV & 6 & $15.00 \%$ \\
\hline \multirow{2}{*}{ ARMD } & 10 & $25.00 \%$ \\
\hline
\end{tabular}

\section{Intraocular pressure (IOP)}

The mean IOP before the injection $12.5 \pm 3 \mathrm{mmHg}$ and ranged from a minimum of $8 \mathrm{mmHg}$ to a maximum $20 \mathrm{mmHg}$.

At $24 \mathrm{~h}$ after injection, the mean IOP was $14.2 \pm 3.54 \mathrm{mmHg}$ and ranged from $9 \mathrm{mmHg}$ minimum of $22 \mathrm{mmHg}$ maximum. There was a significant difference, but still within the normal range value in IOP measured $24 \mathrm{~h}$ after injection compared to

baseline $(\mathrm{p}=0.001)(\mathrm{p}$ value $<0.05)$.

\begin{tabular}{|l|l|l|l|l|l|}
\hline IOP & Mean & $\begin{array}{l}\text { Std } \\
\text { Dev }\end{array}$ & Min & Max & $\begin{array}{l}\text { P value } \\
\text { compared } \\
\text { to } \\
\text { baseline }\end{array}$ \\
\hline $\begin{array}{l}\text { IOP } \\
\text { pre }\end{array}$ & 12.5 & 3 & 8 & 20 & --- \\
\hline $\begin{array}{l}\text { IOP } \\
\text { day } \\
\text { 1 }\end{array}$ & 14.2 & 3.54 & 9 & 22 & $<0.001$ \\
\hline
\end{tabular}

Table 2 shows that, there is a significant difference between IOP after 1 day regarding ranibizumab.

Difference in IOP measured compared to $=0.016)(\mathrm{p}$ value $>0.05)$.

\begin{tabular}{|c|c|c|c|c|c|}
\hline I0P & Mean & $\begin{array}{c}\text { Standard } \\
\text { Deviation }\end{array}$ & Minimum & Maximum & $\begin{array}{c}\text { P value } \\
\text { compared } \\
\text { to baseline }\end{array}$ \\
\hline IOP week 1 & 13.08 & 3.46 & 8 & 20 & 0.016 \\
\hline I0P week 2 & 12.6 & 3.22 & 7 & 19 & 0.593 \\
\hline IOP week 3 & 12.65 & 3.07 & 8 & 20 & 0.361 \\
\hline I0P week 4 & 12.48 & 3.26 & 7 & 20 & 0.844 \\
\hline I0P week 5 & 12.73 & 3.28 & 8 & 21 & 0.118 \\
\hline I0P week 6 & 12.55 & 3.1 & 8 & 20 & 0.66 \\
\hline I0P week 7 & 12.58 & 3.12 & 7 & 20 & 0.538 \\
\hline IOPweek 8 & 12.6 & 3.14 & 8 & 20 & 0.378 \\
\hline
\end{tabular}

Figure 3: IOP before injection, $\mathrm{r} 24 \mathrm{~h}$, 1 week up to 8 weeks after ranibizumab injection. There was no significant difference between the IOP from 1 week up to $8 \mathrm{~W}$ of ranibizumab injection. 


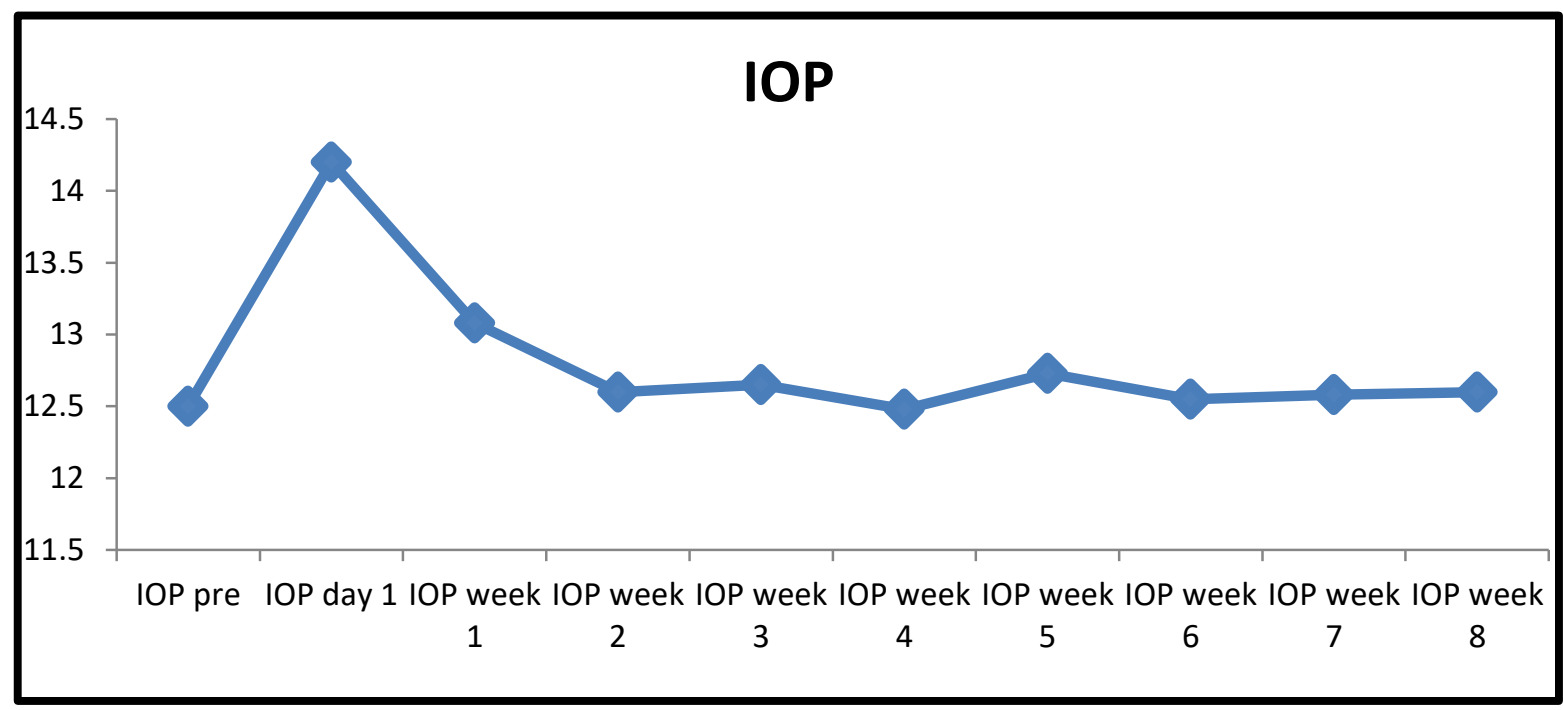

Table 4 shows the IOP changes from $\mathrm{W} 1$ to $\mathrm{W} 8$ (p value $>0.05$ )

\section{Discussion}

Ranibizumab is a recombinant, humanized, monoclonal antibody Fab fragment against vascular endothelial growth factor A (VEGF-A)

Ranibizumab works by slowing the growth of abnormal new blood vessels in the eye and decreasing leakage from these blood vessels.

Intravitreal injection enables highly targeted drug therapy, maximizing therapeutic drug delivery to the posterior pole while minimizing systemic toxicity.

This prospective study included 40 patients who underwent intravitreal injection of $0.05 \mathrm{~mL}$ ranibizumab, and measured IOP in a sitting position before and 24 hours, 1week ,and weekly up to 8 weeks after injection. $\mathrm{y}$, and found that the mean preinjection IOP was $14 \mathrm{mmHg}$ (range, 7-- 22 $\mathrm{mmHg}$ ). IOP was reduced to less than
In the present study, the mean IOP before the injection of $12.5 \pm 3 \mathrm{mmHg}$ and ranged from aminimum of 8 $\mathrm{mmHg}$ to a maximum of $20 \mathrm{mmHg}$. At $24 \mathrm{~h}$ after injection, the mean IOP was $14.2 \pm 3.54 \mathrm{mmHg}$ and ranged from $9 \mathrm{mmHg}$ minimum of $22 \mathrm{mmHg}$ maximum. There was a significant difference but still within the normal range value in IOP measured $24 \mathrm{~h}$ after injection compared to baseline $(\mathrm{p}=$ 0.001 ) ( $\mathrm{p}$ value $<0.05$ ). There was no significant difference between IOP from 1 week up to $8 \mathrm{~W}$ of ranibizumab injection.

In (2008) Kim JE(7) and his
colleague $30 \mathrm{mmHg}$ in $96 \%$ of injections by 15 minutes and in $100 \%$ by 30 minutes that mean it recorded results as same as 
our study after $24 \mathrm{~h}$ after injection, no a significant changes in IOP value.

$\begin{array}{llr}\text { In (2015) } & \begin{array}{l}\text { Weerawat } \\ \text { Middee } \\ \text { and Mayuree } \\ \text { Montriwe(8) }\end{array} \text { also }\end{array}$
studied seventy eyes of 54 patients. Most of them had diabetic macular edema (48\%). The mean IOP \pm standard deviation (SD) before treatment was $13.7 \pm 2.8 \mathrm{mmHg}$. The mean \pm SDs after treatment at $1 \mathrm{~h}, 1$ week, 1 month, 3 months, and 6 months were $11.3 \pm 2.6,13.7 \pm 3.6$, $14.1 \pm 3.3,14.0 \pm 2.3$, and $13.7 \pm 2.4$ $\mathrm{mmHg}$, respectively. There was no need for anti-glaucoma medication(which matched with our study no need for anti-glaucoma medication)(PLoS One. 2015)(9).

In (2009) Gismondi (10)and his colleague did study, IVI causes a considerable short-term transient rise in IOP. The IOP increase after IVIL can be statistically significant at 0 to 30 min after injection in both phakic and pseudophakic eyes, and tends to be greater in shorter eyes.

In Graefe $(\mathbf{2 0 0 8})(11)$ study, four patients had high intraocular pressure after intravitreal ranibizumab0.5 mg, ocular hypertension occurred 1 month after the second ranibizumab injection in patients 1 and 3 , and 1 month after the first ranibizumab in patient 2 . In patient 4 , it occurred several hours after the first ranibizumab injection. In all patients, the IOP increase was sustained across several visits, requiring control with topical glaucoma therapy, and in two cases, the addition of a systemic carbonic anhydrase inhibitor. None of the patients had a previous history of glaucoma, ocular hypertension, or IOP asymmetry, and the IOP was as high as $30,34,46$, and $50 \mathrm{mmHg}$ in the four patients. Severe and sustained ocular hypertension may occur after intravitreal ranibizumab. Although the mechanism of the pressure rise is unknown, all eyes in our series were controlled with medical therapy.

\section{Dedania VS did study in} (2015)(12), with different results to our study, patients undergoing treatment with intravitreal anti-VEGF agents may experience sustained and delayed elevation of IOP. The incidence of sustained elevation of IOP in patients with neovascular age-related macular degeneration varied from $3.45 \%$ to $11.6 \%$, and few patients required surgical management to control IOP. Possible risk factors associated with sustained and delayed elevation of IOP include, but are not limited to, history of glaucoma, phakia, history of glucocorticoid use, and/or extended treatment duration. There are multiple theories explaining the pathogenesis of sustained elevation of IOP, including microparticle obstruction of the trabecular meshwork, intraocular inflammation, and transient elevation of IOP.

In Hoang QV et al. (Feb 2012)(13) study, a greater number of intravitreal anti-vascular endothelial growth factor injections is associated with an increased risk of IOP elevation $>5$ $\mathrm{mmHg}$ on $\geq 2$ consecutive visits in eyes with neovascular AMD receiving intravitreal ranbizumab. To clarify whether the cause of this difference studying changes of IOP with multiple injections is required.

\section{Conclusion and recommendation}

The current study confirms the results of previous studies that showed the safety of initial IV injection of antiVEGF agents for IOP elevation in postinjection two monthes in 
non-glaucomatous patients. However, there might be a tendency to increase IOP in glaucoma cases and repeated injections, so further studies on the safety of repeated injections in glaucomatous patients, on the number of patients, different ophthalmogical disorders, and recommended for measuring IOP within 30min of injection should be carried out.

\section{REFERENCE}

1- Rosenfeld P. A (2016): Reducing Drug Costs to Medicare Testimony before the Senate Special Committee onaaging. http://www.aging.senate.gov /imo/media/doc/hr236pr.pdf. Accessed December 28, 2016.

2- Hutton D, Newman-Casey P, Tavag $M$, et al(2014): Switching to less expensive blindness drug could save medicare part B $\$ 18$ billion over a tenyear period. Health Aff.(Millwood). 2014;33(6):931-939.

3.- Virgili G, Parravano M, Menchini F, et al(2014): Anti-vascular endothelial growth factor for diabetic macular oedema. Cochrane Database Syst Rev ;10:CD007419.

4- Farandos, NM, Yetisen, et al (2014): "Contact Lens Sensors in Ocular Diagnostics".

AdvancedHealthcarehMaterials.

4 (6):792810. doi:10.1002/adhm.20140 0504. PMID 25400274.

5- Pooranee (2015): "Do you know about Intra Ocular Pressure?".Health Education Bureau, Information and Communication Technology Agency, Sri Lanka.Retrieved 2015-11-04.
6- Chan YH (2004): Biostatistics301: Repeated measurement analysis. Singapore Med J.;45(8): 354-369.

7- Kim JE , Mantravadi AV, Hur EY, et al (2008) Send to Am J Ophthalmol. 2008Dec;146(6):9304.e1.doi:10.1016/j.ajo.2008.07.007. Epub 2008 Sep 5.

8- Myers (Provencher) LA, Almeida D and Abràmoff $\mathrm{MD}(2015)$ : Intravitreal Injection Technique: A Primer for Ophthalmology Residents and Fellows. EyeRounds.org. January 6, 2015.

9-PLoS One(2015): $2015 \quad$ Sep 11;10(9):e0137833. doi: 10.1371/journal.pone.0137833. eCollection 2015.

10- Gismondi, Maurizio MD, Salati, et al (2009): Journal of Glaucoma: December 2009 - Volume 18 - Issue 9 - p 658-661 doi: 10.1097/IJG.0b013e31819c4893

11-Graefe's (2008): Archive for Clinical and Experimental Ophthalmology Volume

246, Issue 7, pp 955-958 .

12-Dedania VS and Bakri SJ (2015) pubmed Retina. 2015 May;35(5):841$58 . \quad$ doi: 10.1097/IAE.0000000000000520..

13- Hoang QV, Mendonca LS, Della Torre KE,et al (2012): Effect on intraocular pressure in patients receiving unilateral intravitreal antivascular endothelial growth factor injections. Ophthalmology 2012; 119: 321-326. 